\title{
Review
}

\section{Revisiting retinoblastoma protein phosphorylation during the mammalian cell cycle}

\author{
S. Cooper ${ }^{\mathrm{a}, *}$ and J. A. Shayman ${ }^{\mathrm{b}, \mathrm{a}}$ \\ a Department of Microbiology and Immunology, University of Michigan Medical School, Ann Arbor \\ (Michigan 48109-0620, USA), Fax +1 734764 3562, e-mail: cooper@umich.edu \\ ${ }^{b}$ Nephrology Division, Department of Internal Medicine, University of Michigan Medical School, \\ Ann Arbor (Michigan 48109-0676, USA), e-mail: jshayman@umich.edu \\ Received 16 October 2000; received after revision 13 November 2000; accepted 15 November 2000
}

\begin{abstract}
It is widely accepted that phosphorylation of the retinoblastoma $(\mathrm{Rb})$ protein during the $\mathrm{G} 1$ phase of the mammalian division cycle is a major control element regulating passage of cells into $\mathrm{S}$ phase and through the division cycle. The experiments supporting G1-phasespecific $\mathrm{Rb}$ phosphorylation and the historical development of this idea are reviewed. By making a rigorous distinction between 'growth cessation' and the phenomena of 'cell cycle exit' or 'G1-phase arrest', the evidence for the G1-phase-specific phosphorylation of $\mathrm{Rb}$ protein is
\end{abstract}

reinterpreted. We show that the evidence for G1-phase phosphorylation of $\mathrm{Rb}$ rests on few experiments and a chain of reasoning with some weak links. Evidence is reviewed that growth conditions regulate the phosphorylation of $\mathrm{Rb}$. A growth-regulated control system that is independent of the cell cycle explains much of the evidence adduced to support cycle-specific phosphorylation of $\mathrm{Rb}$. We propose that additional experimental evidence is needed to decide whether there is a G1-phase-specific phosphorylation of $\mathrm{Rb}$ protein.

Key words. G1 phase; cell cycle; G1-phase arrest; phosphorylation.

\section{Why another review of retinoblastoma phosphorylation?}

This is a review of the evidence related to the cellcycle-specific phosphorylation of the Retinoblastoma $\mathrm{Rb}$ protein. As is well understood, reviews of scientific fields are usually summaries of the consensus view of a field. In general, a reviewer has an obligation to describe the main conclusions and key experiments in a field so that the contributions of the various workers to the current or consensus view are presented clearly and equitably. The essential activity of the normal review process is that it summarizes what the field believes, and not what one particular segment of the field believes.

\footnotetext{
* Corresponding author.
}

The evidence for control of cell growth and the cell cycle by G1-phase-specific phosphorylation of $\mathrm{Rb}$ protein has been presented in numerous reviews. It is not necessary to review and summarize the evidence that has been presented often and so ably by many others [1-4]. Therefore, this review has a somewhat different purpose - and this should be understood at the outset. We propose to reexamine the evidence that $\mathrm{Rb}$ protein is phosphorylated in a specific phase of the cell cycle. We do this in order to discern precisely what particular experimental evidence rigorously supports this widely held conclusion, and what evidence is merely consistent with this proposal. This reevaluation of the literature on the subject of cell-cycle-specific $\mathrm{Rb}$ phosphorylation reveals that the evidence for this phenomenon is not as strong as generally believed. 
To anticipate our conclusion, we propose that essentially all of the data regarding G1-phase Rb phosphorylation is merely consistent with the notion or idea that there is a G1-phase phosphorylation event. We examine the chain of reasoning leading to the proposal of G1-phase phosphorylation and show that there is an alternative explanation for much of the data. Finally, we shall review the recent work on the in vitro sequence of phosphorylation steps and relate this work to the proposal that there is a G1-phase phosphorylation of Rb protein. As will be seen, it is possible to have sequential phosphorylation steps demonstrated in vitro without having these steps relate to the proposed in vivo phosphorylation of $\mathrm{Rb}$ protein during the mammalian cell cycle.

G1-phase phosphorylation of $\mathrm{Rb}$ protein is currently viewed as a paradigmatic example of G1-phase control of the mammalian division cycle. As much analysis of the cell cycle is based on the Rb model of cell-cycle-specific phosphorylation, it is important that the experimental basis for the $\mathrm{Rb}$ model be beyond reproach. Furthermore, as the $\mathrm{Rb}$ model is an example for future studies of control of the cell cycle in the G1 phase, it is important to consider what is required to rigorously conclude that there is a G1-phase event during the mammalian division cycle.

Before presenting a detailed analysis of the $\mathrm{Rb}$ literature, we will first present some general ideas regarding the relationship of cell growth and the cell cycle. This analysis will serve as a foundation for discussing the evidence for cell-cycle specific phosphorylation of $\mathrm{Rb}$ protein.

\section{The distinction between cell growth and the passage through the cell cycle}

It has become popular to equate cessation of cell growth with the exit of the cell from the cell cycle. Resumption of cell growth has similarly been equated with reentering the cell cycle. There is an important distinction to be made between 'cell growth' and 'passage through the cell cycle'. A similar distinction should also be made between cessation of growth and 'exiting the cell cycle'.

In order to understand this distinction between cell growth and the cell cycle, consider a growing culture with the cells in the culture being at various points in the division cycle. Consider that the cells are growth arrested by some means so that the cells are now frozen at their particular points in the cell cycle. That is, a cell that was at the start of the cell cycle is now fixed with the characteristics of a cell at the start of the cycle. And a cell at the end of the cycle is now frozen as a cell near the end of the cell cycle. Upon releasing these cells for regrowth, we could agree, for this hypothetical and imaginary example, that resumption of growth was not a 'reentering the cell cycle'. The cells were frozen at particular points in the cell cycle, and resumption of growth was merely the continuation of passage through the cell cycle from the point of arrest. In this example, the cells never left the cell cycle, and thus cannot be said to reenter the cell cycle upon resumption of cell growth.

A more important case is to have cells arrested at different points in the cell cycle, and yet have these cells alter some property of the cell so that the cells have an appearance of all being in the same part of the cell cycle. Specifically, arrest of cell growth will allow cells to accumulate with a particular amount of DNA similar to that in a particular phase of the cell cycle, for example the G1 phase. But as stated here, the cells can be arrested and fixed in particular phases of the cell cycle, with only a superficial appearance that the cells are arrested in the G1 phase of the cell cycle. To be explicit about the language of growth arrest, it is possible to have cells 'arrested with a G1-phase amount of DNA', and yet not be 'arrested at a point in the G1 phase'. The implications of this apparently paradoxical distinction will become apparent in the discussion that follows.

Another distinction must be made explicit, and that is the distinction between growth of the culture which leads to an increase in cell numbers as well as total cell mass, and the growth of individual cells. Unless otherwise noted, the discussion here will always be related to individual cells increasing their cell mass during the division cycle.

With these distinctions in hand, we can look at the evidence for G1-phase-specific phosphorylation of $\mathrm{Rb}$ protein from a new perspective.

\section{An industrial analogy to the cell cycle}

Before presenting the cellular concepts, it is useful to present an industrial analogy to illuminate the distinction between the general process of cell growth and the specific subset of processes that comprise the cell cycle.

Consider an assembly line where workers assemble an automobile in a sequence of steps. When car production ceases due to a lack of demand, no new car assemblies are started, but cars on the assembly line are completed so no cars remain unfinished.

When the decision to cease production is given, all workers are immediately given layoff notices. However, the workers continue to work until there is no more work at their section of the assembly line. In practice, this means that workers at the start of the assembly line stop working first. Then workers in the middle of the assembly line stop working. Finally, workers at the end of the assembly line stop working. After the time required for complete car assembly, there is an accumulation of unemployed workers and an assembly line with no partly assembled cars.

Superficially, it now looks as if the idled employees in this factory are all in identical situations. One might even say that the workers are aligned at the same point in the work process and that when work resumes they will start 
working at the same time; that is, work will resume 'synchronously'.

Let us consider, however, what happens upon resumption of car assembly. As the assembly line starts up, the first workers to return to the job are the ones at the start of the assembly line, specifically those who were laid off first when automobile manufacture ceased. As the car assembly proceeds, workers in the middle of the assembly line resume work. Finally, the last workers who were laid off, the workers at the end of the assembly line, resume work. The unemployed workers are not aligned and identical. There is a memory of their original position, and the workers do not resume work 'synchronously' upon resumption of car manufacture.

From this simple analogy, we see that while all workers received the layoff notice at the same time, their history varied with their position on the assembly line. At some point the workers all looked the same (unemployed), but as we have seen, the workers were not identical with respect to resumption of work.

If we equate the getting the layoff notice with cessation of cell growth, and position in the assembly line with position in the cell cycle, we can now see that cessation of cell growth and exit from the cell cycle are quite different. When growth ceases, cells become aligned with respect to one particular property, DNA content. This common DNA content, however, does not mean the cells are identical. It does not even mean that the cells are aligned at a particular point in the cell cycle. More crucial and important is the idea that affecting cells identically in all stages of the cell cycle (i.e. stopping cell growth in all cells in the culture irrespective of their position in the cell cycle) leads to the apparent arrest of cells in a particular phase of the cycle.

It is important to see that cessation of cell growth - the growth that was occurring similarly throughout the cell cycle - is not identical with exiting the cell cycle. When growth ceases, initiation of DNA synthesis ceases (analogous to cessation of starting new car assembly). Eventually all cells are found with a DNA content equivalent to the amount of DNA in a G1-phase cell. This is because the cell completes all S, G2 and M phases for cells that were in $\mathrm{S}, \mathrm{G} 2$ and $\mathrm{M}$ phases at the time that growth ceased. This completion process produces the widely found experimental result where cells that are starved or whose mass increase is arrested for any reason are found to accumulate with a G1-phase amount of DNA.

As with the laid-off workers, the cells - now all with a G1-phase amount of DNA - are not identical and do not resume entry into the cell cycle in a synchronous manner. Just as the workers resume work in an order reminiscent of the order in which they stopped work, cells resume entry into DNA synthesis in an order resembling their original position in the cell cycle. Alignment of cells so that all cells have a G1-phase DNA content does not mean cells are arrested at a particular point in the cell cycle. Furthermore, it does not mean the cells will resume passage through the cell cycle from a particular cell cycle point and proceed through the cycle in a synchronous manner.

\section{Reexamination of G1-phase arrest}

It is important to be explicit about what is meant by a synchronized culture. We propose that a synchronized culture is one that truly mimics the division cycle of a normal, growing cell. This idea, in theory, is actually widely accepted. All workers using synchronization methods aspire to this ideal of normal progression of a synchronized culture through the division cycle. In practice, however, it is difficult to demonstrate that cells are synchronized and reflect the normal cell cycle of unperturbed cells. It is extremely labor intensive and experimentally difficult to measure successive cell divisions in a culture to demonstrate that cells are synchronized and exhibit synchronized divisions.

Synchronization methods are viewed as efficient ways to get large numbers of cells in particular phases of the division cycle. The problem arises when one asks whether cells that are aligned with a particular cell property are actually synchronized. We propose that it is not correct to term a culture synchronized, or arrested in a particular phase at a particular point of the cell cycle, merely because all cells may have a G1-amount of DNA. A distinction between 'alignment' for a particular property, and 'cell-cycle arrest' at a particular point, will be illustrated here.

Consider that as cells pass through the division cycle they move through a series of states representative of sequential points in the division cycle. As shown in figure 1, these can be labeled $a-n$. Although we can imagine the different states as being associated with particular and different chemical processes, it is also possible to consider the various states during the cell cycle as related to varying amounts of any particular material. For example, as cytoplasm increases continuously during the division cycle, we can associate the different states with different amounts of cytoplasm, or different amounts of any particular part of the cytoplasm.

Now consider that the cells moving through the cell cycle are growth arrested by some procedure so that the various cytoplasmic states are preserved, but initiation of DNA synthesis - though not DNA synthesis itself - ceases. Cells in S, G2 and M phases continue to complete DNA synthesis and progress through mitosis, producing a population of cells all with a G1-phase amount of DNA. As shown in figure 1, cells may be aligned with a G1-phase amount of DNA, but these cells are not identical or synchronized $[5,6]$. To see why these cells are not synchronized, consider that cell size (or any other 


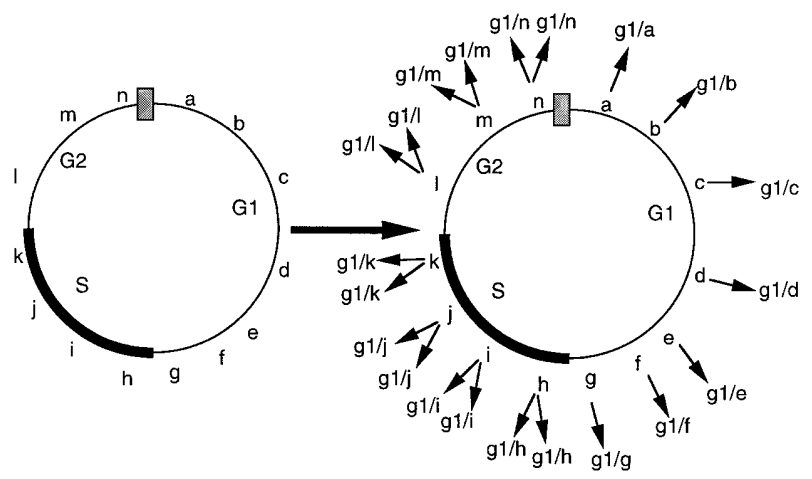

Figure 1. Arresting growing cells to produce a cell population all with a G1-phase amount of DNA. The cell cycle is viewed as has having two components, one the well-known phases of the division cycle - G1, S, G2 and M - and an additional property $(\mathrm{a}-\mathrm{n})$ that varies continuously throughout the division cycle (diagram at left). The variation of state (for simplicity one could just imagine this state to be the amount of any particular protein that is made continuously throughout the division cycle and thus increases throughout the division cycle) is not changed upon arrest of cell growth by inhibition or starvation. However, when cell growth is inhibited (indicated by arrow toward right), cells that are in the S, G2 or M phases proceed through these phases and divide to produce two daughter cells, each with a G1-phase amount of DNA (right figure). These daughter cells are labeled with the DNA content (g1) and the state condition $(a-n)$. Thus, while all cells have a G1-phase amount of DNA, they are not arrested at the same point in the division cycle. Only if all cells had, for example, a G1-phase amount of DNA and a 'c' state representative of cells in the middle of the G1 phase of the division cycle could one describe these cells as being arrested at a point in the G1 phase or arrested 'in the G1 phase'.

property that is part of the cell mass) increases continuously during the division cycle. When growth is inhibited, cells in S, G2 and M phases complete the S, G2 and $\mathrm{M}$ phases to produce a culture where all cells have a G1-phase amount of DNA. The cells produced by growth arrest are not identical and are actually all of different sizes. These cell sizes reflect the original distribution of sizes in cells of different ages during their passage through the cell cycle. The cells that are aligned with a particular amount of DNA (equivalent to that in the G1 phase of the cell cycle) are therefore not representative of the size or state associated with the G1-phase in the original growing culture. During the normal growth of cells, each cell age is associated with a particular cell size between that of newborn cell size and dividing cell size. Because cells in the aligned culture do not have a narrow size distribution, they do not represent cells of a particular cell age during the division cycle. In fact, the cells resulting from starvation in figure 1 have the same breadth of sizes (over a factor of approximately two-fold) as the original cells in the growing culture.

Of course, the completion of the division cycle of S and G2/M cells during conditions leading to G1-phase arrest is an a priori necessity if arrest with a G1-phase amount of DNA is to be observed. If passage through the terminal phases of the cell cycle did not occur, the arrested

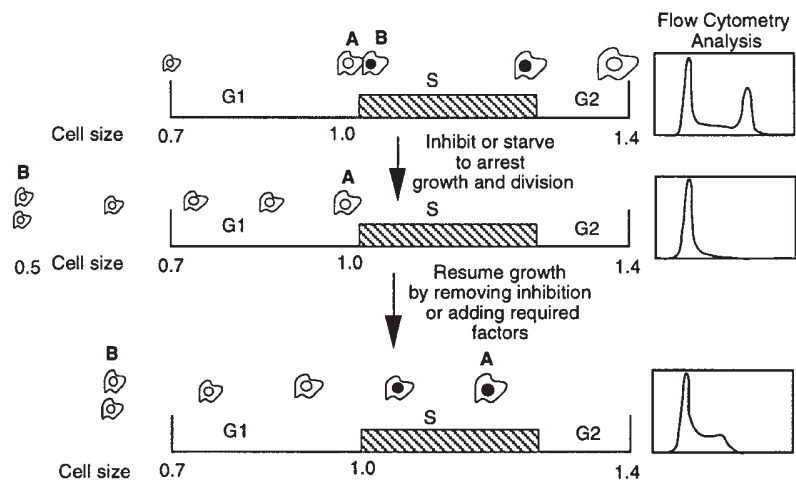

Figure 2. Starvation aligns cells with a G1-phase amount of DNA, but these cells are not synchronized. Consider cells growing between sizes of approximately 0.7 and 1.4 . There are cells in all phases of the division cycle, as indicated by the idealized flow-cytometer analysis at the right (upper panel). DNA synthesis, illustrated by the filled nucleus, initiates in the middle of the division cycle, at a size of approximately 1.0. Although cells in all phases of the cycle are illustrated, consider the two cells of approximately size 1.0, one just before (A), and one just after (B), the start of S phase. The cell with a G1DNA content (cell A) does not initiate DNA synthesis and remains a cell with a G1DNA content. The S phase cell (cell B), on the other hand, proceeds through division and produces two cells of size 0.5 (center panel). These daughter cells are of size 0.5 because the mass does not increase during the period of inhibition; when the cells coming from the early $\mathrm{S}$ phase cells divide, the resulting daughter cells are half the size of the cells that were late in G1 phase and did not divide. The cells produced after starvation (A, B in middle panel) therefore differ in size by a factor of 2 . All of the other cells in the original culture are of sizes intermediate between size 0.5 and 1.0, and all have a G1amount of DNA. They are not arrested or synchronized at a particular point in the G1 phase of the cycle following starvation, for the cells are actually approximately one doubling time apart. After resumption of growth is allowed (lower panel), the first cells to initiate DNA synthesis (enter S phase) are the cells that were just about to enter S phase (A) but were inhibited by the starvation or inhibition protocol. The cells that arose by division (from cell B) must grow for one extra doubling time before they initiate DNA synthesis. Initiation of DNA synthesis is not synchronized, being spread over one doubling time.

cells would not all have a G1-phase amount of DNA, and the cells would not be 'arrested in the G1 phase of the division cycle'. If starvation produces cells with a G1-phase amount of DNA, but of varying sizes or states (fig. 1), then it is possible, and even expected, that the aligned cells would not be synchronized.

An idealized representation of this analysis in terms of what is expected after cells are arrested with a G1-phase amount of DNA and then released from the arrest conditions (either starvation or inhibition) is shown in figure 2. Consider that size varies continuously during the division cycle. Consider further that starvation or inhibition leading to cessation of cell growth freezes the amount of material in each of the cells at the amount present at the time of starvation or inhibition. Cells passing through the cell cycle during normal, unrestricted growth are shown in the upper panel in figure 2. Cells vary in size from newborn size to twice newborn size (on average) at the 
instant of division. Consider two cells - one just before and one just after the start of S phase - at the instant of synchronizing cells. If the cell size at initiation of DNA synthesis is 1.0, the cell just before the start of S phase is approximately size 0.999 , and the cell just after the start of S phase is approximately size 1.001 .

Because the cell mass in the individual cells does not change during the extended period of starvation or inhibition, the cell mass of the cell that was at the end of the G1 phase remains approximately 0.999 . The cell that had just started S phase, while not changing its cell mass (i.e. not changing its cytoplasmic mass), proceeds through $\mathrm{S}$, $\mathrm{G} 2$ and M phases to produce two newborn cells. These newborn cells have a mass of approximately 0.5 , and both newborn cells have a G1-phase amount of DNA. Similar considerations indicate that all cells now have a G1-phase amount of DNA, but all cells have different sizes depending on their cell size at the instant of cessation of cell growth. Sizes vary from approximately 0.5005 (i.e. half of 1.001) to 0.999 .

Upon resumption of growth, the cells would not be expected to enter $\mathrm{S}$ phase in a synchronous manner. The cells with size 0.999 will enter S phase or resume DNA synthesis almost immediately, as they only have to make 0.001 units of cell mass to get to size 1.0. The cells of size 0.5005 will require approximately one full doubling time to achieve a cell mass of 1.0. This is because cell mass doubles, by definition, in one doubling time. Cells between these two extremes initiate $\mathrm{S}$ phase at variable times after resumption of cell growth. The cells produced by starvation where all cells have a G1-phase amount of DNA are not necessarily synchronized. The G1-arrested cells, upon resumption of growth, start DNA synthesis in an asynchronous manner and eventually divide in an asynchronous manner.

Reflecting back on the industrial analogy presented above, we can associate the pool of unemployed workers with the collection of cells with a G1-phase amount of DNA, and the completed assembly line with the completed S, G2 and M phases of the division cycle. Because the resumption of work on the assembly line is not 'synchronized', the cells aligned with a G1-phase amount of DNA are not synchronized. The cells resume initiation of DNA synthesis in an asynchronous manner.

A complete analysis of this proposal has been presented $[5,6]$ with appropriate experimental support using results in the literature. We distinguish between 'aligned' cells that have a particular property present in all cells (in this case, G1-amount of DNA), and 'synchronized' cells, where cells truly and accurately reproduce the events during the division cycle of normal, exponentially growing cells. We conclude that growth arrest may produce cells with a G1-phase amount of DNA, but these cells are not equivalent to normal G1-phase cells in a culture growing exponentially in unlimited growth.
In addition to active starvation and inhibition protocols, other conditions can lead to growth arrest or G1-phase arrest in what is sometimes considered a more biologically relevant fashion. For example, allowing cells to grow on a plate to confluence or quiescence leads to arrest of cells with a G1-phase amount of DNA. Recently it has become popular to refer to such cells as being in a particular 'out-of-cycle' phase entitled 'G0'. Because cells in the 'G0 phase' have the same amount of DNA as cells with a G1-phase amount of DNA, such quiescent cells are sometimes referred to as cells in the 'G1/G0 phase'. Similarly, cells arrested at the 'restriction point' can be considered as being equivalent to the cells aligned with a G1-phase amount of DNA. But the same analysis that we have presented for starvation and inhibition synchronization protocols applies to arrest by confluence of entry into quiescence. In such cells cell growth ceases and cells pass through the $\mathrm{S}, \mathrm{G} 2$ and $\mathrm{M}$ phases to produce a population of cells all with a G1-phase amount of DNA. But these cells are similarly not arrested with a particular size or cell state so that the cells are arrested at a point in the G1 phase of the cell cycle.

\section{Rb protein and the regulation of cell growth}

$\mathrm{Rb}$ protein is understood to be a negative regulator of cell growth. Loss of $\mathrm{Rb}$ function leads to uncontrolled cell growth, as indicated by the appearance of malignancies. 'Activating' $\mathrm{Rb}$ protein by dephosphorylation leads to sequestering by the $\mathrm{Rb}$ protein of transcription factors proposed to be essential for continued passage through the cell cycle. Conversely, phosphorylation of $\mathrm{Rb}$ protein is proposed to control cell growth.

The $\mathrm{Rb}$ gene is believed to be a suppressor of tumor formation because the retinoblastoma ( $\mathrm{Rb}$ or $\mathrm{pRB})$ gene is inactivated in $\mathrm{Rb}$ cells [7] and other tumors [8-13]. Cytogenetic and molecular analyses have also indicated that blastoma cells often have two defective copies of the $\mathrm{Rb}$ gene $[8,14-18]$. Direct support of the proposal that the $\mathrm{Rb}$ gene is a tumor suppressor comes from the demonstration that introduction of the normal gene into Rb cells led to a loss of tumorigenicity [19]. It is now believed that inactivation of the $\mathrm{Rb}$ gene leads to oncogenesis, not only in eye tissue, but also in a variety of cell types [20-23]. We can now turn to early experiments on analyzing the mechanism by which $\mathrm{Rb}$ protein controls the passage of cells through the cell cycle. But before doing so, it is important to explicitly state what is not proposed here.

\section{Biochemical and kinetic analysis of $\mathbf{R b}$ function}

We strongly emphasize that we do not take issue with the importance of $\mathrm{Rb}$ protein as a regulator of cell growth. 
That is not the purpose of the analysis presented here. The interactions of $\mathrm{Rb}$ protein with its phosphorylating and dephosphorylating enzymes, its relationship to cyclins and its action downstream to regulate the initiation of DNA replication are not at issue here. Here we concentrate only on the problem of whether or not $\mathrm{Rb}$ protein is phosphorylated in a cell-cycle specific manner.

In the following discussion we will deal primarily with experiments on the kinetics of variation of $\mathrm{Rb}$ protein. None of this analysis should be taken as critiquing or disagreeing with the vast amount of work on the biochemistry of $\mathrm{Rb}$ protein. $\mathrm{Rb}$ protein may affect various transcription factors, and $\mathrm{Rb}$ may be phosphorylated by specific kinases and dephosphorylated by specific phosphatases. All of these interactions are accepted. But we suggest that the existence of these interactions and biochemical functions do not bear on the problem of whether or not $\mathrm{Rb}$ protein is phosphorylated in a cell-cycle-specific manner.

\section{Tumor virus transformation and the mechanism of action of $R \mathbf{b}$ protein}

Speculations regarding the possible mechanism of action of $\mathrm{Rb}$ protein come from early studies of DNA tumor viruses. The start of the reasoning process is the observation that a viral transforming product can form a specific complex with $\mathrm{Rb}$ [24-26]. Further studies suggested a link between the ability of the viral protein to complex with $\mathrm{Rb}$ and the transforming function of the virus protein [26-28]. These viral studies supported the notion that $\mathrm{Rb}$ is a suppressor of tumor growth because it could be envisioned that the association of the viral proteins with the $\mathrm{Rb}$ protein would alleviate growth suppression due to the $\mathrm{Rb}$ protein and thus allow cells to exhibit a transformed phenotype.

The next step in the reasoning process came from the generally accepted idea that transforming viruses 'stimulate G1-arrested cells to enter the cell cycle' [29]. This conclusion comes from the general observation that normal, untransformed cells that are allowed to grow to confluence are arrested with a G1-phase amount of DNA. These confluent cells are generally described as 'arrested in the G1 phase'. Infection of these cells with transforming virus allows cells that integrate the virus to restart growth and escape the 'contact inhibition' processes that stops growth of untransformed cells. As usually described, transformation allows cells to grow in all phases of the division cycle [30-37].

The reasoning sequence may be summarized: (i) confluent cells are proposed to be arrested in a particular phase of the division cycle, the G1 phase; (ii) transformation of cells by certain viruses allows these 'G1-phase' cells to grow in all phases of the division cycle; (iii) this growth is an escape from G1-phase arrest; (iv) cells arrested with a G1-phase amount of DNA are arrested at a particular point in the G1 phase; and (v) virus transformation thus counteracts a specific G1phase arrest process. We will return to this line of reasoning below.

The next crucial step in the analysis was the finding that SV40 $\mathrm{T}$ antigen complexes with $\mathrm{Rb}$ protein but only to underphosphorylated $\mathrm{Rb}$ protein [38]. This implied that the poorly phosphorylated or hypophosphorylated form of $\mathrm{Rb}$ protein is the form active in growth suppression.

This analysis led a number of groups to investigate the possibility that $\mathrm{Rb}$ phosphorylation varied during the division cycle of mammalian cells and that cycle-specific phosphorylation of $\mathrm{Rb}$ protein controlled passage of cells through the division cycle. A number of groups [29, 39-46] have presented experimental evidence that the $\mathrm{Rb}$ protein is phosphorylated and dephosphorylated in a cell-cycle-dependent manner. More precisely, it was concluded that $\mathrm{Rb}$ is phosphorylated in the G1 phase of the division cycle. A general model to explain these observations, and to relate phosphorylation to control of the cell cycle, is that phosphorylation of $\mathrm{Rb}$ relieves the growth suppressing action of the unphosphorylated $\mathrm{Rb}$ protein. This phosphorylation allows the cell to enter the $\mathrm{S}$ and $\mathrm{G} 2 / \mathrm{M}$ phases. If phosphorylation of $\mathrm{Rb}$ does not occur, cells will not enter the $\mathrm{S}$ phase and will not proceed through the cell cycle.

To summarize this chain of reasoning in molecular terms, and according to the current consensus view [3, 47], the dephosphorylated form of $\mathrm{Rb}$ is a negative control element. Upon phosphorylation of the $\mathrm{Rb}$ protein at a point in the G1 phase, the negative action of the $\mathrm{Rb}$ protein is eliminated, and the cell is allowed to move from the G1 phase into the $\mathrm{S}$ phase, that is the cells are able to initiate DNA replication. One biochemical mechanism explaining cell-cycle control by the $\mathrm{Rb}$ protein is that the hypophosphorylated form sequesters the E2F transcription factor. Upon Rb phosphorylation, E2F is released. The newly released E2F transcription factor then induces the expression of various genes associated with the initiation of DNA replication [48-50].

The variation of $\mathrm{Rb}$ phosphorylation during the division cycle has been succinctly summarized [51]: 'the pRB phosphorylation state fluctuates as the cell passes through the division cycle. In cycling cells $\mathrm{pRB}$ is found in its active underphosphorylated form only during the early period of the G1 phase'. And further: 'pRB phosphorylation in late G1 and its dephosphorylation in late $\mathrm{M}$ phase are considered the two critical events regulating pRB's growth-restraining activities'.

Fitting in with this model is the additional idea that cyclin-dependent kinases may regulate the phosphorylation of $\mathrm{Rb}$ protein $[50,52]$. Support comes from studies associating cyclin-dependent kinases (specifically cdk4/6 activated by cyclin D and cdk2 activated by cyclin E) with 
regulation of $\mathrm{Rb}$ phosphorylation [53, 54]. Since cyclins are thought to be the prime example of a cell-cyclespecific regulatory protein, this finding supports the general role of a cycle-specific phosphorylation-dephosphorylation pattern for $\mathrm{Rb}$ protein.

Additional support for a cell-cycle-associated phosphorylation-dephosphorylation of $\mathrm{Rb}$ comes from the proposal that there is a specific mitotic phosphatase that removes the phosphate groups from $\mathrm{Rb}$ protein at mitosis, thus restoring the dephosphorylated or hypophosphorylated form of Rb protein at the start of the G1 phase [55, 56]. The proposed growth-suppressing activity of the dephosphorylated $\mathrm{Rb}$ protein must then be alleviated by phosphorylation of $\mathrm{Rb}$ protein in the G1 phase if cells are to proceed onto the next $\mathrm{S}$ and $\mathrm{G} 2 / \mathrm{M}$ phases. The association of this phosphatase activity with the mitotic phase of the cell cycle was accomplished by arresting cells in the mitotic phase of the division cycle using nocodazole. At this time no physiological experiments on growing, uninhibited, unperturbed cells indicating a cell-cycle-specific activation of phosphatase activity have been presented.

\section{Growth control of Rb phosphorylation/ dephosphorylation}

Superimposed upon this proposed cell-cycle-specific phosphorylation pattern is an additional control system where the growth state of the cell regulates, or is associated with, the phosphorylation state of $\mathrm{Rb}$ protein. Many studies have found that in rapidly growing cells all the $\mathrm{Rb}$ protein is in the hyperphosphorylated state. When growth is inhibited, $\mathrm{Rb}$ is dephosphorylated, and hypophosphorylated $\mathrm{Rb}$ appears [39]. Additional studies of Daudi cells grown exponentially or inhibited by serum starvation, $\alpha$-interferon or phorbol ester also indicated that growing cells had a preponderance of hyperphosphorylated $\mathrm{Rb}$ protein and inhibition of growth led to a loss of phosphorylation [41]. In this same study, U937 cells that were unable to be inhibited by $\alpha$-interferon did not exhibit the dephosphorylation of $\mathrm{Rb}$ when $\alpha$-interferon was added. Another report demonstrated that in human leukemia cells induced to undergo growth arrest with sodium butyrate or DMSO, dephosphorylation of the RB protein is not G1-phase restricted but also occurs in $\mathrm{S}$ and $\mathrm{G} 2 / \mathrm{M}$ cells [57]. In this study it was found that while all of the $\mathrm{Rb}$ protein in cells with a G1-phase amount of DNA cells is hypophosphorylated, cells in S and G2 have significant detectable amounts of hypophosphorylated RB as well as hyperphosphorylated RB protein. Thus, $\mathrm{Rb}$ hypophosphorylation can be induced in S- and G2-phases as well as the G1 phase when growth is inhibited. Dephosphorylated $\mathrm{Rb}$ is thus not restricted to the early part of the G1 phase.
Experiments from our laboratory support the converse proposal, that hyperphosphorylation is not restricted to later stages of the cell cycle. Exponentially growing cells, whether in growing in suspension or adhering to a surface, can grow with no evidence of hypophosphorylated $\mathrm{Rb}$ protein [58].

In contrast to the evidence presented supporting the role of $\mathrm{Rb}$ protein regulating the passage of cells through the division cycle, and in particular, allowing exit from the G1 phase, some reports indicate that alternative pathways in a cell can override the $\mathrm{Rb}$ control system [59-61]. Thus, different experiments implicate c-myc, oncogenic Ras protein and cyclin E as cell constituents that could allow cell growth even in cells where phosphorylation of $\mathrm{Rb}$ protein was unable to be carried out. For example, expression of cyclin E protein can trigger S-phase entry in cells expressing pRB lacking 10 out of the 15 cyclin-dependent-kinase phosphorylation sites [60].

Thus, although there are a number of published papers supporting the view that $\mathrm{Rb}$ phosphorylation is an essential step in passage through the cell cycle, there are some results that may give pause to a complete acceptance of the current $\mathrm{Rb}$ phosphorylation-dephosphorylation model.

\section{Reanalysis of transforming virus control of cell growth}

It is important to explicitly cite the weak link in the initial reasoning process that led to the suspicion or suggestion that there could be a relationship between $\mathrm{Rb}$ phosphorylation and a specific phase of the division cycle. The weak links in the reasoning process are the two proposals listed above: (iii) this growth is an escape from G1 phase arrest, and (iv) cells arrested with a G1-phase amount of DNA are arrested at a particular point in the G1 phase. These two ideas are the ones that specifically lead to the conclusion that transforming viruses 'stimulate G1-arrested cells to enter the cell cycle'. We do not suggest that there is any problem with the proposal that transforming viruses stimulate quiescent or confluent cells to grow (that is, increase in cell mass) and divide (increase in cell number). It is important to be rigorous in the language used to describe the stimulation of quiescent cells to grow. By the term 'quiescent' we do not mean anything other than the operational idea that such cells are not growing. We realize that some use this term to mean the cells are 'out of the cycle'. There is no operational way to determine whether such nongrowing cells are out of the cycle or merely arrested with a G1-phase amount of DNA but not truly 'out of the cycle'. But the propositions that the quiescent cells are arrested in the G1 phase of the division cycle - because they have a G1-phase amount of DNA - and that cells are stimulated to 'enter' the cell cycle - which implies that the quiescent or 
non-growing cells were 'out of the cycle' - are ideas that are open to question. This idea has been presented in figures 1 and 2 , and in the discussion at the start of this review.

To reiterate, the alternative conclusion from the observation of virus transformation is that cessation of growth (due to confluence) leads to dephosphorylated $\mathrm{Rb}$ and that viral transformation stimulates growth which leads to the production of phosphorylated $\mathrm{Rb}$. These transformations can occur irrespective of the cell cycle situation of the cells. We suggest that because the quiescent cells are not arrested at a point in G1 phase but merely with a G1phase amount of DNA, it is not proper to conclude from the viral transformation studies that $\mathrm{Rb}$ protein is specifically phosphorylated in a G1-phase specific manner. We shall address the experiments that deal directly with the proposal of G1-phase phosphorylation of Rb protein. It is important to look at experiments that support G1-phase phosphorylation of $\mathrm{Rb}$ protein in order to see whether the results are as strong as they are purported to be. However, before turning to these studies, it will be helpful to have an alternative view of how the phosphorylation of $\mathrm{Rb}$ protein may be regulated. Specifically, we propose that (i) the growth conditions regulate the observed phosphorylation pattern, and (ii) this regulation is independent of the cell cycle. The dephosphorylation of $\mathrm{Rb}$ protein that is observed in cells that have a G1-phase amount of DNA is a result of the poor growth conditions that lead to the arrest of cells with a G1-phase amount of DNA.

\section{An alternative model for $\mathbf{R b}$ phosphorylation}

We propose that in growing cells with a normal cell cycle, there is no G1-phase-specific phosphorylation of $\mathrm{Rb}$ protein. In the normal division cycle of exponentially growing cells, whether malignant or not, there is no phosphorylation-dephosphorylation cycle. We will unify the two control aspects of Rb protein, control of phosphorylation by growth state and the apparent cell-cyclespecific phosphorylation pattern, by demonstrating that growth state control of phosphorylation can actually lead to the incorrect conclusion that there is a G1-phase phosphorylation step.

Because the current model of G1-phase phosphorylation is so widely supported by a number of published experimental papers, it is important that we present not only our alternative explanation but also explain, fully and clearly, how the other published work is also accommodated to our model. After presenting our view of Rb phosphorylation, we will present an extensive analysis of a number of relevant papers in order to show that our proposal is actually consistent with, or in some cases not contradicted by, experiments in the literature.

If one were to summarize a number of experiments (analyzed in full detail below) and present a single, idealized explanation of why it is believed that $\mathrm{Rb}$ is phosphorylated in the G1 phase of the division cycle, that explanation would be that cells in the G1 phase have both hypoand hyperphosphorylated $\mathrm{Rb}$ protein, whereas the cells in the $\mathrm{S}$ and $\mathrm{G} 2 / \mathrm{M}$ phases have only hyperphosphorylated $\mathrm{Rb}$ protein. Given this result, the following widely accepted scenario arises. Cells are born at division with dephosphorylated or hypophosphorylated $\mathrm{Rb}$ protein. This protein would suppress growth and prevent passage of these cells into the $\mathrm{S}$ and $\mathrm{G} 2$ phases if the Rb protein were not phosphorylated. This is because the dephosphorylated $\mathrm{Rb}$ protein sequesters a required transcription factor, E2F. While this sequestration of E2F is active, no initiation of $\mathrm{S}$ phase can occur. At some point in the middle of the G1 phase, the Rb protein is phosphorylated. If a collection of G1 phase cells is analyzed, this model predicts that both hypo- and hyperphosphorylated $\mathrm{Rb}$ protein would be found. This is because the G1-phase cells are collectively cells from both early in the G1 phase (hypophosphorylated) and cells later in the G1 phase (hyperphosphorylated). Cells that are phosphorylated (in the late G1 phase) now start S phase and complete the division cycle, so we find that $\mathrm{S}$ and $\mathrm{G} 2 / \mathrm{M}$ cells have only the hyperphosphorylated form of $\mathrm{Rb}$ protein. At the end of the division cycle, a specific phosphatase presumably removes the phosphates from the hyperphosphorylated $\mathrm{Rb}$ protein (at mitosis) to produce hypophosphorylated $\mathrm{Rb}$ protein in the new daughter cells, now with a G1phase amount of DNA.

Our alternative model explains this finding - two forms of $\mathrm{Rb}$ in $\mathrm{G} 1$ phase cells and one form of $\mathrm{Rb}$ in $\mathrm{S} / \mathrm{G} 2 / \mathrm{M}$ phase cells - by proposing that growing cells actually have phosphorylated $\mathrm{Rb}$ protein throughout the division cycle and that there is no G1-phase-specific phosphorylation step.

Our model of $\mathrm{Rb}$ phosphorylation is presented in figure 3 . If cells are allowed to grow without any restraint (for example cells plated at very low cell density), then all of the $\mathrm{Rb}$ protein is phosphorylated (fig. $3 \mathrm{a}$ ). Cells that are in a suboptimal growth state - such as adherent cells that are in close contact and have some contact inhibition have a dephosphorylated form of $\mathrm{Rb}$ protein (fig. $3 \mathrm{~b}$ ). (It should be considered that it is very difficult to have adherent cells growing on the surface of a dish avoid contact inhibition, as even single isolated cells that grow and divide to produce a clone will have cells that are relatively close to each other. Thus, contact inhibition is very difficult to avoid and may occur at densities far below what may be considered overcrowded conditions.) As the cell density increases, a mixture of two types of cells with a G1-phase amount of DNA are produced. One cell type is from the growing fraction or the cells that are not too crowded. The other cell type arises from the inhibited or suboptimal growth fraction where growth is inhibited by contact inhibition. The G1 phase cells from 


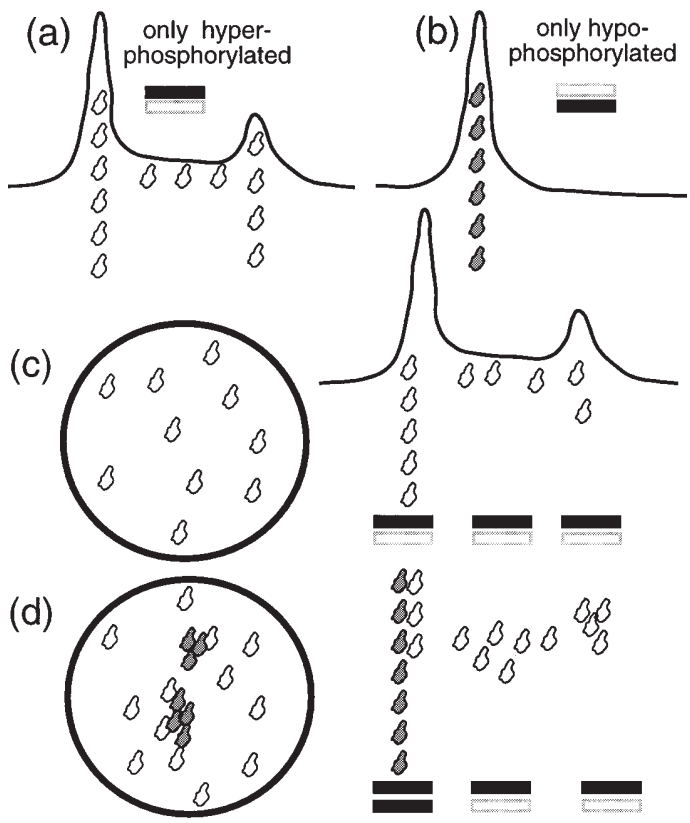

Figure 3. Explanation of how growth conditions can affect the G1-phase phosphorylation pattern, although in growing cells there is no cell-cycle variation in $\mathrm{Rb}$ phosphorylation. In $(a)$ an idealized representation of growing cells is presented. There is a normal cell-cycle flow-cytometric pattern with G1 and G2 peaks, with an S-phase valley between the two peaks. The unshaded cells in this diagram are proposed to all have the hyperphosphorylated form of $\mathrm{Rb}$ with no cell-cycle-specific variation in phosphorylation pattern. In $(b)$ the shading indicates cells that have been arrested in their growth (by medium conditions, contact inhibition or other unknown factors) and have accumulated with a G1-phase amount of DNA. The growth conditions that lead to cell growth arrest are presumed to also give the dephosphorylated form of $\mathrm{Rb}$. Although the cause-effect relationship of growth cessation and phosphorylation state is not explicitly an issue here, one may consider that the phosphorylation state is merely a correlate of growth cessation and may or may not be causative. The next panels illustrate what is proposed to occur for cells grown at low cell densities $(c)$, and higher cell densities $(d)$. Under conditions of low cell density $(c)$, because the cells are growing in balanced, exponential growth, all cells are proposed to have only the phosphorylated form, and there is no difference between the $\mathrm{Rb}$ phosphorylation pattern in the different phases of the cell cycle. At higher cell concentrations $(d)$ the adherent types of cells are a mixed population with some cells being arrested (the shaded cells) and others growing vigorously and oblivious to the other cells in the medium. When such a mixture is analyzed, it is seen that the $\mathrm{S}$ and $\mathrm{G} 2$ phases give the same pattern as in the dilute case, whereas the cells with a G1-phase amount of DNA show both bands; one band is from the growing cells $(a)$ and the other band is from the arrested or inhibited cell fraction $(b)$.

the growing cells contain hyperphosphorylated Rb protein. This is because all the growing cells contain hyperphosphorylated $\mathrm{Rb}$. The inhibited, nongrowing cells with a G1-phase amount of DNA contain hypophosphorylated $\mathrm{Rb}$ protein. This is because nongrowing cells produce dephosphorylated $\mathrm{Rb}$ protein. The cells with $\mathrm{S}$ and $\mathrm{G} 2 / \mathrm{M}$ phase amounts of DNA are produced only by the growing fraction of cells. This is true by definition, since otherwise the cells would be arrested and have a G1-phase amount of DNA. In cells with the $\mathrm{S}$ and $\mathrm{G} 2 / \mathrm{M}$ amounts of DNA, the cells from the growing fraction, there would be only one type of $\mathrm{Rb}$ protein, the hyperphosphorylated form.

To recapitulate, the cells with $\mathrm{S}$ and G2/M amounts of DNA define, by their existence, cells not arrested with a G1-phase amount of DNA. These are growing cells. The cells with a G1-phase amount of DNA are a mixture of growing cells (with phosphorylated $\mathrm{Rb}$ ) that lead to $\mathrm{S}$ and G2/M phase cells, and growth-inhibited cells or cells with suboptimal growth conditions (with dephosphorylated $\mathrm{Rb})$ that are arrested with a G1-phase amount of DNA. Thus, two forms of Rb are found in cells with a G1-phase amount of DNA and one form in the cells with an S or G2/M amount of DNA.

The model presented in figure 3 implies the following predictions. First, exponentially growing cells that are not subject to any inhibitory conditions would not have any mixture of $\mathrm{Rb}$ phosphorylation states in cells with a G1-phase amount of DNA. Second, and perhaps more important, finding two types of $\mathrm{Rb}$ protein in the cells with a G1-phase amount of DNA would be dependent on growth conditions. Cells growing exponentially under dilute conditions and without any contact inhibition (nonadherent cells do not appear to exhibit contact inhibition similar to that of adherent cells) would have no hypophosphorylated $\mathrm{Rb}$ protein in G1-phase cells. With increasing density (i.e. increasing contact inhibition), there would be a shift in the $\mathrm{Rb}$ pattern to hypophosphorylation.

Experiments in our laboratory have confirmed both of these predictions [58]. When cells are grown exponentially in unlimited conditions, no hypophosphorylated $\mathrm{Rb}$ protein is found. All of the $\mathrm{Rb}$ protein is found in the hyperphosphorylated form, and this form is found throughout the cell cycle [58]. Furthermore, studies with adherent NIH3T3 cells indicated that the appearance of hypophosphorylated $\mathrm{Rb}$ protein was dependent on cell density. When cells were grown at very low densities, hypophosphorylated $\mathrm{Rb}$ protein was not found; all of the $\mathrm{Rb}$ protein was found in the hyperphosphorylated form. These results directly support the model proposed in figure 3. It is important to note that the complete phosphorylation of $\mathrm{Rb}$ protein required growth down to be approximately $5 \%$ of confluent density. Thus, even when it does not appear that cells are 'overgrown' in the usual sense of the word, the cells may be overgrown with respect to $\mathrm{Rb}$ phosphorylation and dephosphorylation.

\section{On the criteria for a satisfactory synchrony experiment}

Before proceeding with our analysis of direct experiments on $\mathrm{Rb}$ phosphorylation during the cell cycle, we must present a few ideas to guide this analysis. First, we 
are skeptical of synchronization methods that are based on treating all cells in a culture identically. Refer to figures 1 and 2 for an explanation of why we do not accept such methods. This critique has been presented in detail $[5,6]$. It is also important to recognize that there are criteria for synchronization that should be met in order to demonstrate that a particular collection of cells are synchronized ([62], chapter 3). Let us briefly describe some of these criteria:

1) If the cells in a synchronized culture are proposed to be equivalent to newborn cells or cells very early in the division cycle, there should be a period of no, or little, cell division for a relatively long period.

2) When a synchronized division occurs in a cell population, the time required for the increase in cell number at the time of division should be a relatively small fraction of the interdivision time; that is, the cell number should double over a relatively short period of time.

3) There should be at least two independent and reproducible cycles of synchronized growth.

4) Any experimental result found during the first division cycle should be found similarly in the second cycle. This avoids or minimizes artifacts resulting from the synchronization procedure.

5) The lengths of the two successive cell cycles should be similar, and the timing and size of the cycle-specific event should be the same in both cycles.

6) The interdivision times of the synchronized culture should be the same as the doubling time of the original culture. This is important for judging the 'normality' of the synchronized cells.

7) Any results obtained by a synchrony method should be consistent with available observations on cells growing in unperturbed exponential growth. This means that one should be able to see, for example, the sequential passage of cells through different DNA contents as cells pass through the division cycle.

One can summarize essentially all of the data on Rb phosphorylation during the division cycle where starvation or inhibition synchronization techniques have been used by stating that the criteria for synchronization we have listed here have not been satisfied. We therefore suggest that one should be skeptical of experiments that use such starvation or inhibition methods for synchronization. This implies that one should be skeptical of many of the experiments that support G1-phase-specific phosphorylation of $\mathrm{Rb}$ protein.

We realize that it has been argued that cumulative stochastic variations lead to the obliteration of synchronized divisions. This proposal has been used to explain why so many synchrony methods do not yield synchronized divisions. The recent production of synchronized cells by Helmstetter (personal communication) using a mammalian 'baby machine' [63] that gives three clear synchronized divisions suggests that the lack of synchronized divisions may actually be an indication that the cells that have been proposed to be synchronized are actually not synchronized.

This general conclusion regarding synchronization also applies to systems that are proposed to be more natural approaches to cell-cycle analysis, such as the stimulation of lymphocytes by mitogens. Not only is the history of each of the lymphocytes unknown (i.e. the age of each lymphocyte is unknown as they may have been produced by division over many years), but it is not clear that such lymphocytes produce a culture with a cell cycle that is the same as the cell cycle of growing cells. Just because lymphocytes have a G1-phase amount of DNA does not mean that these cells are arrested at a particular point in the division cycle (see figs 1 and 2).

Finally, and perhaps most important, we do not accept the notion of a G0 phase as being a specific place where growth-arrested cells come to rest. We mention this as a separate item because there has been a proliferation of papers proposing that cells enter into a special 'out-of-cycle' phase, the G0 phase. A detailed critique of the G0 proposal for one specific experiment on $\mathrm{G} 0$ has been published [ 64 , 65]. We are well aware of the ubiquitous nature and widely used citation of the G0 phase (sometimes as G0, sometimes as G0/G1 when a decision between these two phases is not possible). A complete analysis of the $\mathrm{G} 0$ problem has been reviewed ([62], page 402) and the arguments will not be restated here. The analyses presented in figures 1 and 2 are applicable to the problem of G0 cells. Merely because cells are arrested with a G1-phase amount of DNA does not mean the cells have accumulated at a particular point in the cell cycle (G1-phase arrest) or at a particular point out of the cycle (G0).

\section{Revisiting experimental support for G1-phase- specific Rb phosphorylation}

Turning now to the direct experimental evidence for cell-cycle-specific Rb phosphorylation, let us look at an instructive example [39] where the proposal that $\mathrm{Rb}$ phosphorylation is related to the cell cycle was first shown by stimulating human peripheral blood lymphocytes. Resting lymphocytes had only the least phosphorylated Rb. After the cells were stimulated, slower migrating (i.e. hyperphosphorylated) forms of $\mathrm{Rb}$ were found. As noted above, we do not feel that this lymphocyte system is a model for the division cycle. An earlier analysis of c-myc synthesis during the division cycle demonstrated that such stimulated lymphocytes could lead to artifacts of interpretation [66]. We suggest the proper conclusion from the analysis of stimulated lymphocytes is that resting cells have hypophosphorylated $\mathrm{Rb}$ protein and when growth is stimulated, $\mathrm{Rb}$ pro- 
tein is phosphorylated. That the lymphocytes have a G1phase amount of DNA is independent of the phosphorylation state of $\mathrm{Rb}$ protein.

The second step in their analysis [39] was to study CV1P cells, a monkey kidney cell line that they proposed 'can be synchronized by growth arrest'. Cells were grown to confluence 'at which point contact inhibition arrests further cell division'. The cells were then replated sparsely in fresh medium 'to allow the synchronous entry into the cell cycle'. Following replating, cells were collected at 2-h intervals to examine the phosphorylation state of $\mathrm{Rb}$ protein by western blotting. It was found that in the 'growth-arrested cells' the Rb protein appeared as a single, least-phosphorylated band. As growth resumed following replating, the $\mathrm{Rb}$ protein was observed to undergo increasing amounts of phosphorylation as indicated by the retardation of the $\mathrm{Rb}$ protein in polyacrylamide gels. Similar results were found in T24 bladder carcinoma cell line using an identical protocol. The conclusions drawn from these experiments are that 'these results demonstrated that $\mathrm{Rb}$ was progressively phosphorylated during G1 phase and that the maximal phosphorylation occurred at the G1/S junction. Dephosphorylation of $\mathrm{Rb}$ was apparent as cells reentered G1'.

The data presented [39] do not fulfill the criteria for synchronization that we have presented above. One should consider these confluent cells - and thus growtharrested cells - subject to the same analysis that we have used when describing serum starvation to synchronize cells. Confluent cells may have a G1-phase amount of DNA, but these cells are not arrested at a specific point in the division cycle. It is most interesting to note that in these experiments two independent starvation experiments were performed that were offset by $16 \mathrm{~h}$. The first set covered hours $0-16$, and the second set hours $18-32$. (We assume this allowed a more efficient collection schedule, as two parallel experiments were running simultaneously.) The early points were plated at $1.5 \times 10^{6}$ cells per plate, and the later points were on plates with $3 \times 10^{6}$ cells per plate. Whatever conclusions may be made are thus weakened by the fact that just at the breakpoint between the two sets of plates there is a sudden break in the $\mathrm{Rb}$ protein pattern. It is difficult to decide whether the results observed are due to the experimental design or due to the starvation-refeeding protocol. A telling result is the finding that after $32 \mathrm{~h}$ of regrowth the cells resembled an unsynchronized culture. This indicates that the cells are very likely not synchronized, as a second cycle of synchrony cannot be observed. In fact, this observation supports the proposal made in figure 2 where it is predicted that after approximately one interdivision time the cells that had a G1-phase amount of DNA will return to the normal DNA pattern.

The last set of experiments studied cells that were stimulated to differentiate by certain chemical agents. It was found that when cells were stimulated to differentiate, which entails a cessation of growth, there was a loss of phosphate from $\mathrm{Rb}$ protein [39]. The authors suggest that this result supports the idea of a cell-cycle-specific phosphorylation event by stating, 'Since cellular differentiation is associated with arrest in G0/G1, dephosphorylation of $\mathrm{Rb}$ in differentiated cells further supported the conclusion that $\mathrm{Rb}$ protein is hypophosphorylated in non-proliferating cells'. The basic argument is that arresting cells in the G1-phase (i.e. not allowing cells to perform the G1-phase phosphorylation event) produces cells with a G1-phase amount of DNA and a hypophosphorylated $\mathrm{Rb}$ protein.

We suggest an alternative explanation. The cells all eventually have a G1-phase amount of DNA because initiation of DNA replication is prevented and cells in S, G2 and M phases complete these phases and divide to produce cells with a G1-phase amount of DNA. Concurrently, and independently, the $\mathrm{Rb}$ protein is dephosphorylated, leading to a collection of cells with dephosphorylated $\mathrm{Rb}$ protein and cells with a G1-phase amount of DNA.

As we have noted above, the cellular growth state affects $\mathrm{Rb}$ phosphorylation, with a low phosphorylation of $\mathrm{Rb}$ protein associated with poor growth conditions. The differentiation studies are consistent with the model we have proposed and do not directly support the idea that during the G1-phase there is a specific time when Rb is phosphorylated.

A similar critique can be applied to studies of primary human umbilical vein endothelial cells [29]. These cells require endothelial cell growth factor for growth; without this factor, the cells are unable to proliferate. It was concluded that the arrested cells were 'likely to be in G0/G1'. As explained above, we do not accept that the factorstarved cells are equivalent to cells in the G1 phase of a normal, growing population. Even the use of the word 'likely' suggests a certain reticence in proposing that the cells are synchronized. We suggest these cells are actually growing under suboptimal conditions; this is the reason that these cells have hypophosphorylated $\mathrm{Rb}$ protein. The appearance of the hypophosphorylated form of $\mathrm{Rb}$ was associated with cell growth arrest, and the hyperphosphorylated form was found in cells stimulated to grow. We accept this experimental result, and as noted above, we have no disagreement with the experimental observation. But also as discussed above, the arrested cells are not models of the G1 phase. Therefore no conclusions can be made regarding the cycle-specific phosphorylation or dephosphorylation of $\mathrm{Rb}$.

More to the point is an experiment in which HeLa cells were grown in spinner culture and separated by elutriation into fractions enriched in the various phases of the cell cycle. Flow-cytometric analysis of the DNA content of these cells indicated that the successive fractions went from 8 to $87 \%$ of the cells with a G1-phase amount of 
DNA. Analysis of the $\mathrm{Rb}$ protein revealed 'a dramatic shift in the mobility of the Rb species ... as cells progress from $\mathrm{G} 1$ to $\mathrm{S}$ and G2/M'. The fractions predominantly of cells with a G1-phase amount of DNA had the hypophosphorylated $\mathrm{Rb}$ protein, whereas the $\mathrm{S}$ and $\mathrm{G} 2 / \mathrm{M}$ phase cells contained the hyperphosphorylated $\mathrm{Rb}$ protein. As can be seen in figure 3, this is just what is expected if, prior to elutriation, the cells were composed of two populations: a growing population with cells in all phases of the division cycle and a nongrowing population due to contact inhibition of the cells on the surface of a plate. Although one may call these cells 'overgrown', it is possible to consider (as we have explicitly noted above) such cells being at a cell density much below what might be considered a state of overgrowth and still get the problems illustrated in figure 3.

Additional experiments on the cell cycle relied on a double block synchrony method with an initial starvation for methionine (for $48 \mathrm{~h}$ ) followed by addition of methionine and the simultaneous inhibition of DNA synthesis by hydroxyurea treatment (16 h) [44]. Growth was allowed by removing hydroxyurea. The result of this 'synchronization procedure' was that the cells with a G1-phase amount of DNA had hypophosphorylated $\mathrm{Rb}$ protein; after a period of growth, cells with S- and G2/M-phase amounts of DNA had hyperphosphorylated $\mathrm{Rb}$ protein. As we have explained at length above, we do not accept that this procedure produces synchronized cells that are a model of the cell cycle for cells growing exponentially in medium without inhibition. More to the point, synchronization procedures may and can introduce artifacts that cannot be eliminated in these doubly inhibited cells. In particular, the harsh treatment of cells with methionine starvation followed by hydroxyurea treatment should be suspect with regard to the introduction of artifacts. The double inhibition method was followed up by synchronizing cells by serum starvation. We have dealt with this method above, and can only reiterate our reluctance to accept serum starvation synchronization as a method suitable for the analysis of the division cycle.

To summarize our analysis, these results [29] are actually consistent with our model. We feel that the proper conclusion is that these experiments do not support the existence of a G1-phase phosphorylation step.

An example of the relationship between growth rate or growth state and $\mathrm{Rb}$ phosphorylation and how it can appear as a G1-phase phosphorylation of Rb protein comes from a study of inhibition of mink lung cells (Mv1Lu) by TGF $\beta$ [67]. Cells that were inhibited in their growth, whether by overgrowth on a plate or by addition of the inhibitor TGF $\beta$, had only hypophosphorylated $\mathrm{Rb}$ protein. When cells that were density-arrested by contact inhibition were allowed to regrow after trypsinization and replating, it was observed that the $\mathrm{Rb}$ was rephosphorylated approximately $2 \mathrm{~h}$ before DNA synthesis resumed.
The conclusion was that $\mathrm{Rb}$ protein was phosphorylated in the late-G1 phase of the cell cycle. Our reading of this paper leads to a different conclusion. First, the internal evidence presented in this paper indicates that the cells are not actually synchronized. This is primarily indicated by the long times over which a particular event occurs after synchronization. But second, and more important, all of the observations in this paper are consistent with the model proposed here. Specifically, cells that are inhibited in growth have hypophosphorylated $\mathrm{Rb}$ protein and cells that are allowed to grow have hyperphosphorylated $\mathrm{Rb}$ protein. And the phosphorylation of $\mathrm{Rb}$ is not necessarily a G1-phase specific phenomenon.

Perhaps the best experiments supporting the proposal that $\mathrm{Rb}$ protein is phosphorylated in the G1 phase of the division cycle are those in which elutriation was used to study the cell cycle [40]. In these experiments, Hela cells were analyzed by elutriation in two different ways. First, cells were synchronized by collecting the early elutriation fractions (smallest cells) and inoculating these cells into fresh media to produce synchronized growth through the division cycle. In theory this method can certainly produce a synchronized culture. The elutriation procedure is not subject to the criticisms leveled against starvation procedures. That the culture was synchronized was indicated by the pattern of $\mathrm{G} 1 / \mathrm{S} / \mathrm{G} 2 / \mathrm{M}$ phase cells following inoculation. Associated with growth through the division cycle was a characteristic variation in the phosphorylation pattern with the early, youngest cells having only hypophosphorylated $\mathrm{Rb}$ and phosphorylation increasing during $\mathrm{S}$ phase. A decrease in phosphorylation appeared as the cells entered the next G1 phase. Two other experiments in the same vein were to use elutriation to prepare cells that were in different phases of the cell cycle. The pattern of $\mathrm{Rb}$ phosphorylation in these fixed cells was studied, and the results were interpreted according to the current model, with hypophosphorylated cells in the G1 phase and hyperphosphorylation occurring in the later phases of the division cycle.

The model presented in figure 3 explains the two post-elutriation analyses. If the cells to be analyzed were grown such that there were two cell populations, a growing set and a nongrowing set, one would find the G1-phase cells enriched in arrested cells, and this would contribute to the picture that G1-phase cells have hypophosphorylated $\mathrm{Rb}$ and $\mathrm{S}$, and $\mathrm{G} 2 / \mathrm{M}$ phase cells have hyperphosphorylated Rb. Again, we emphasize that even cells that are not clearly overgrown may exhibit characteristics of growth arrest due to contact inhibition in localized regions of the plate. More difficult to explain are the elutriation synchrony results. Nevertheless, a careful reading of the experimental protocol suggests that this experiment must also be reevaluated. In this experiment, the cells were placed at $4{ }^{\circ} \mathrm{C}$ before elutriation and throughout the elutriation procedure. The cells were 
then warmed up to initiate growth. The cells may have been perturbed by this cooling procedure, and may have had the $\mathrm{Rb}$ protein dephosphorylated. Then, upon inoculation into fresh media at $37^{\circ} \mathrm{C}$, a shift-up in temperature may have caused perturbations and artifacticious periodicities that led to the observed variation in phosphorylation during the synchronized growth.

Whether or not the model we have presented in figure 3 is correct, the analysis we have presented indicates that the model for cell-cycle-specific phosphorylation of $\mathrm{Rb}$ protein should be reevaluated. Out of the numerous experiments that have been presented as supporting the current G1-phase Rb phosphorylation model, if one disregards experiments that are clearly not able to be used for analyzing the normal cell cycle (e.g. overgrowth and dilution of cells, serum starvation, double-block inhibitions), then we feel that perhaps only one paper is able to support the entire edifice of cell-cycle regulation of $\mathrm{Rb}$ phosphorylation. Clearly, such an important point requires more support and less ambiguous experiments.

We have pointed out that additional support for the general model of $\mathrm{Rb}$ phosphorylation varying during the cell cycle of growing cells comes from the identification of a mitotic phosphatase that can remove phosphates from $\mathrm{Rb}$ protein $[55,56]$. The inhibitor, nocodazole, was used to isolate mitotic cells as part of the support for this proposal of a cell-cycle-specific dephosphorylation step. However, it is not clear that the phosphatase is present only in mitotic cells during the normal growth cycle. No experiments indicate that the specific activity of the phosphatase is higher in the nocodazole-inhibited cells, or that the phosphatase is absent in G1 and S phase cells. Nor are experiments on exponentially growing cells presented that indicate that the phosphatase activity is higher in one specific phase. Even the finding that electroporation of an active phosphatase into G1 phase cells prevented both $\mathrm{Rb}$ phosphorylation and entry into $\mathrm{S}$ phase [68] does not necessarily support the cycle-specific action of this phosphatase. Such an experiment could lead to side effects by dephosphorylation of many other proteins that could prevent growth and subsequent entry into $S$ phase. These experiments are consistent with the view that the phosphatase leads to arrest with a G1-phase amount of DNA, but not necessarily arrest in the G1 phase of the division cycle.

This reanalysis indicates that experiments generally accepted as directly demonstrating the cell-cycle phase or G1-phase-specific phosphorylation of $\mathrm{Rb}$ protein are somewhat weaker than previously thought.

\section{In vitro sequential phosphorylation of Rb protein}

The most recent model of $\mathrm{Rb}$ phosphorylation during the division cycle is the proposal presented by Harbour et al.
[50] for the modification of $\mathrm{Rb}$ protein by cyclins. The model is most clearly presented in the conclusion to that paper:

Our results suggest that phosphorylation of the C-terminal region of $\mathrm{Rb}$ by cyclin $\mathrm{D}-\mathrm{Cdk} 4 / 6$ triggers an initial intramolecular interaction with the central pocket domain that inhibits HDAC binding, thereby blocking active transcriptional repression by the pocket. This interaction facilitates a second phosphorylation-independent interaction of the C-terminal region with the pocket. The subsequent interaction is required for cyclin E-Cdk2 to access S-567, which is buried at the A-B interface. Phosphorylation of S-567 disrupts the A-B interface, preventing $\mathrm{Rb}$ from binding and inactivating $\mathrm{E} 2 \mathrm{~F}$. In this model, the $\mathrm{Rb}$ functions of active repression and inactivation of E2F are lost successively through phosphorylation by cyclin D-Cdk4/6 and then cyclin E-Cdk2, respectively. Cyclin D-Cdk4/6 is likely to be the kinase that normally disrupts HDAC binding and blocks active repression in vivo because it is activated in G1 before cyclin E-Cdk2 [4]. If this is the case, then during the interval in G1 between activation of cyclin D-Cdk4/6 and activation of cyclin E-Cdk2, Rb is not able to actively repress transcription, but it can still bind and inhibit E2F. Inactivation of E2F would not be prevented until near the end of G1, when cyclin E-Cdk2 is activated. Such a progressive loss of activities may allow differential regulation of genes involved in cell cycle progression and/or apoptosis [50].

As can be seen, the identification of a sequential series of biochemical transformations of the $\mathrm{Rb}$ protein by various cyclin-dependent kinases is associated with various stages of the G1 phase. This is summarized in their final figure (redrawn here as fig. 4) where it is seen that the transformations are associated with particular phases of the G1 phase. The problem with this conclusion is that it is based on the assumption that there is a sequential activation of the different cyclin-dependent kinases in the G1 phase. It must be realized that at no point is there any evidence presented [50] to show that the various transformed states of $\mathrm{Rb}$ protein are associated with particular cell ages during the division cycle. The model presented in figure 4 is based solely on the assumption that the evidence for sequential appearance and activity of cyclins D and $\mathrm{E}$ is correct. There is no experimental evidence associating the particular $\mathrm{Rb}$ phosphorylation states with different times during the G1 phase.

The fact that there are sequential biochemical transformations the $\mathrm{Rb}$ phosphorylation-E2F release pathway does not automatically mean that these transformations are occurring over time. As a trivial counterexample, merely because there are biochemical transformations in the synthesis of an amino acid such as phenylalanine does not mean that these are associated in any way with par- 


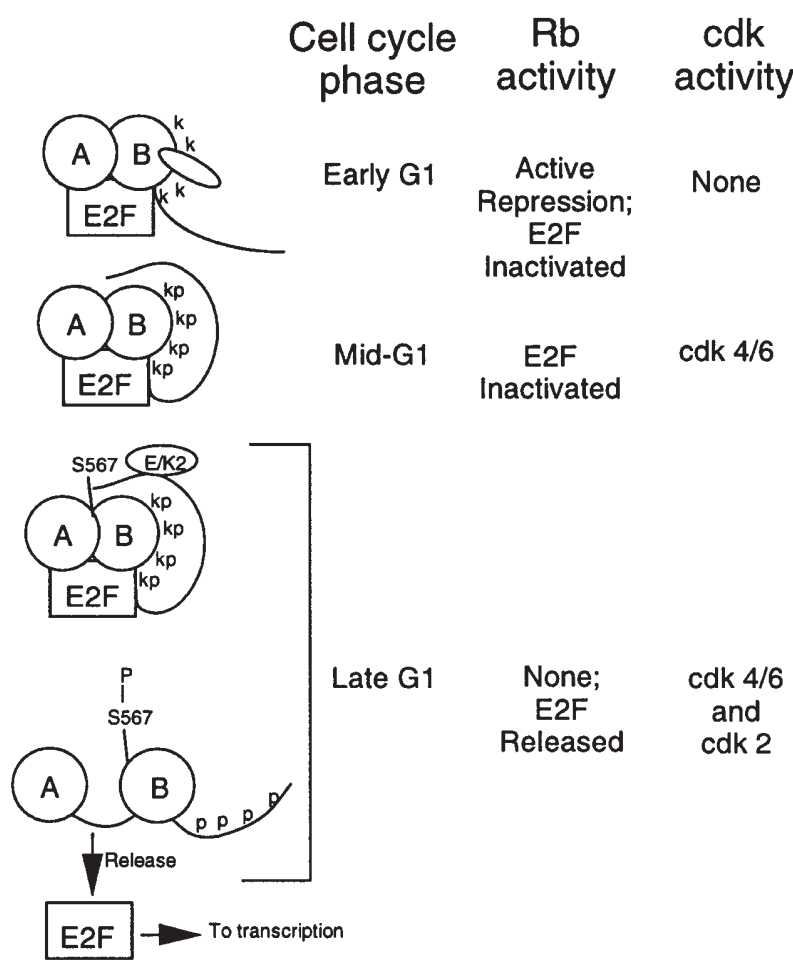

Figure 4. The model of Harbour et al. [50], redrawn from their figure 7. As shown here, "phosphorylation of $\mathrm{Rb}$ initiates sequential intramolecular interactions between the C-terminal region and the pocket domain that result in a progressive loss of $\mathrm{Rb}$ functions as cells move through G1'. The detailed model is discussed fully in the text.

ticular phases of the cell cycle. Rather, for amino acid biosynthesis it is assumed that the biochemical transformations are independent of the cell cycle.

\section{Restatement of the central questions}

The questions we pose here may be listed to summarize the essential points: Are there any experiments demonstrating sequential phosphorylation of $\mathrm{Rb}$ protein at particular phases of the mammalian division cycle or G1 phase that use unperturbed synchronized cells where the results are consistent with the criteria for a good synchrony experiment? and, Are there any experiments demonstrating any particular variation during the G1 phase of the mammalian division cycle that use unperturbed synchronized cells where the results are consistent with the criteria for a good synchrony experiment?

These questions imply a point that should be explicitly stated. By emphasizing mammalian cells, it is implied that evidence in yeast for variation of protein expression during the division cycle does not relieve us of the responsibility to demonstrate this variation in mammalian cells. The discussion starting this review on the distinction between passage through the cell cycle and cell growth clearly demonstrated that merely aligning cells with a particular DNA content does not mean that there is a specific time during the cell cycle at which a particular function acts or is expressed. A cell function involved in cell growth during all phases of the division cycle, when inhibited, could lead to the production of cells with a G1-phase amount of DNA. It is further implied in the questions posed above that merely demonstrating that increasing a cyclin leads to the shortening of the G1 phase does not mean that the cyclin acts during the G1 phase; it could also mean that the cyclin merely speeded up growth throughout the cycle [69]. Finally, the idea of an unperturbed synchrony experiment means that the synchrony should be such that the cells are not starved or inhibited in order to produce a culture that is aligned for a particular property (such as DNA content) where the cells may not be synchronized and where artifacticious results may found.

Given these questions, we conclude that it is not clear that in exponentially growing cells there is a variation in $\mathrm{Rb}$ phosphorylation during the G1 phase of the division cycle.

\section{Rb protein regulates cell growth, not the cell cycle}

A more positive conclusion can actually be drawn from the almost unremitting negativity of this review. Although there are problems with the proposal that $\mathrm{Rb}$ protein regulates cell proliferation by a specific cell-cycle regulatory pattern or cell-cycle modification program, it is possible to now clarify how we should describe the action of $\mathrm{Rb}$ protein.

$\mathrm{Rb}$ protein regulates cell growth throughout the cell cycle, and not the passage of the cell through the cell cycle. As a simple example, let us say that $\mathrm{Rb}$ protein controlled total protein synthesis and regulated the ability of the cell to transcribe messenger (mRNA) for protein synthesis. It is proposed here that $\mathrm{Rb}$ protein can have such a function, and control cell proliferation, without having to propose a cell-cycle-specific function for $\mathrm{Rb}$ protein. If the dephosphorylated form of $\mathrm{Rb}$ was inhibitory for cell growth and mass accumulation, one would observe cells arrested with a G1-phase amount of DNA.

The ideas presented here were first enunciated approximately 2 decades ago [70]. At that time it was proposed that there are no G1-phase-specific events and that the G1 phase existed when the interdivision time or mass doubling time of a mammalian cell was greater than the sum of the $\mathrm{S}+\mathrm{G} 2+\mathrm{M}$ phases $[62,69]$. According to this view of the mammalian division cycle, the G1 phase is the time when biosynthetic processes begun at the start of the previous $\mathrm{S}$ phase are completed. This viewpoint, 
referred to as the continuum model, has been supported by a large number of experimental observations $[62,71]$. The analysis presented here now demonstrates that the $\mathrm{Rb}$ phosphorylation system is consistent with the continuum model.

Acknowledgements. Comments on the manuscript were offered by Lawrence Mathews, Richard Jove, Charles Helmstetter and Joel Swanson; these comments led to major improvements in the presentation. Charles Helmstetter was extremely helpful in his suggestions and comments. Alexandra Cooper, as ever, is a devoted editor who made this paper clearer than it would have been otherwise. This work was funded by a Biomedical Partnerships Grant from the Office of the Dean of the University of Michigan Medical School, and a grant from the University of Michigan Cancer Committee, and grants (to J.A.S.) from the National Institutes of Health (DK39255 and DK41487), as well as a Merit Review Award from the Department of Veterans Affairs (to J.A.S.).

1 Weinberg R. A. (1995) The retinoblastoma protein and cell cycle control. Cell 81: $323-330$

2 Weinberg R. A. (1992) The retinoblastoma gene and gene product. Cancer Surveys 12: $43-57$

3 Hatakeyama M. and Weinberg R. A. (1995) The role of RB in cell cycle control. Progress in Cell Cycle Research 1: 9-19

4 Sherr C. J. (1996) Cancer cell cycles. Science 274: 16721677

5 Cooper S. (1998) Mammalian cells are not synchronized in G1phase by starvation or inhibition: considerations of the fundamental concept of G1-phase synchronization. Cell Prolif. 31: $9-16$

6 Cooper S. (1997) G1 and S phase gene expression cannot be analyzed in mammalian cells synchronized by inhibition. Microbial and Comparative Genomics 2: 269-273

7 Lee W. H., Bookstein R. and Lee E. Y. (1988) Studies on the human retinoblastoma susceptibility gene. J. Cell. Biochem. 38: $213-227$

8 Friend S. H., Bernards R., Rogelj S., Weinberg R. A., Rapaport J. M., Albert D. M. et al. (1986) A human DNA segment with properties of the gene that predisposes to retinoblastoma and osteosarcoma. Nature 323: 643-646

9 Toguchida J., Ishizaki K., Sasaki M. S., Ikenaga M., Sugimoto M., Kotoura Y. et al. (1988) Chromosomal reorganization for the expression of recessive mutation of retinoblastoma susceptibility gene in the development of osteosarcoma. Cancer Res. 48: 3939-3943

10 Shew J. Y., Ling N., Yang X. M., Fodstad O. and Lee W. H. (1989) Antibodies detecting abnormalities of the retinoblastoma susceptibility gene product (pp110RB) in osteosarcomas and synovial sarcomas. Oncogene Res. 4: 205-214

11 Harbour J. W., Lai S. L., Whang-Peng J., Gazdar A. F., Minna J. D. and Kaye F. J. (1988) Abnormalities in structure and expression of the human retinoblastoma gene in SCLC. Science 241: $353-357$

12 T'Ang A., Varley J. M., Chakraborty S., Murphree A. L. and Fung Y. K. (1988) Structural rearrangement of the retinoblastoma gene in human breast carcinoma Science 242: 263 266

13 Yokota J., Akiyama T., Fung Y. K., Benedict W. F., Namba Y., Hanaoka M. et al. (1988) Altered expression of the retinoblastoma (RB) gene in small-cell carcinoma of the lung. Oncogene 3: $471-475$

14 Cavenee W. K., Dryja T. P., Phillips R. A., Benedict W. F., Godbout R., Gallie B. L. et al. (1983) Expression of recessive alleles by chromosomal mechanisms in retinoblastoma. Nature 305: $779-784$
15 Dryja T. P., Rapaport J. M., Joyce J. M. and Petersen R. A. (1986) Molecular detection of deletions involving band q14 of chromosome 13 in retinoblastomas. Proc. Natl. Acad. Sci. USA 83: $7391-7394$

16 Fung Y. K., Murphree A. L., T'Ang A., Qian J., Hinrichs S. H. and Benedict W. F. (1987) Structural evidence for the authenticity of the human retinoblastoma gene. Science 236: $1657-$ 1661

17 Lee W. H., Bookstein R., Hong F., Young L. J., Shew J. Y. and Lee E. Y. (1987) Human retinoblastoma susceptibility gene: cloning, identification, and sequence. Science 235: 1394-1399

18 McGee T. L., Yandell D. W. and Dryja T. P. (1989) Structure and partial genomic sequence of the human retinoblastoma susceptibility gene. Gene 80: $119-128$

19 Huang H. J., Yee J. K., Shew J. Y., Chen P. L., Bookstein R., Friedmann T. et al. (1988) Suppression of the neoplastic phenotype by replacement of the RB gene in human cancer cells. Science 242: 1563-1566

20 Palmero I. and Peters G. (1996) Perturbation of cell cycle regulators in human cancer. Cancer Surv. 27: 351-367

21 Sherr C. J. and Roberts J. M. (1995) Inhibitors of mammalian G1 cyclin-dependent kinases. Genes Dev. 9: 1149-1163

22 Hall M. and Peters G. (1996) Genetic alterations of cyclins, cyclin-dependent kinases and Cdk inhibitors in human cancer. Adv. Cancer Res. 68: 67-108

23 Yamasaki L. (1999) Balancing proliferation and apoptosis in vivo: the Goldilocks theory of E2F/DP action. Biochim. Biophys. Acta 1423: M9-15

24 Dyson N., Howley P. M., Munger K. and Harlow E. (1989) The human papilloma virus-16 E7 oncoprotein is able to bind to the retinoblastoma gene product. Science 243: 934-937

25 Whyte P., Buchkovich K. J., Horowitz J. M., Friend S. H., Raybuck M., Weinberg R. A. et al. (1988) Association between an oncogene and an anti-oncogene: the adenovirus E1A proteins bind to the retinoblastoma gene product. Nature 334: 124-129

26 DeCaprio J. A., Ludlow J. W., Figge J., Shew J. Y., Huang C. M., Lee W. H. et al. (1988) SV40 large tumor antigen forms a specific complex with the product of the retinoblastoma susceptibility gene. Cell 54: 275-283

27 Egan C., Bayley S. T. and Branton P. E. (1989) Binding of the $\mathrm{Rb} 1$ protein to E1A products is required for adenovirus transformation. Oncogene 4: 383-388

28 Horowitz J. M., Yandell D. W., Park S. H., Canning S., Whyte P., Buchkovich K. et al. (1989) Point mutational inactivation of the retinoblastoma antioncogene. Science 243: 937-940

29 DeCaprio J. A., Ludlow J. W., Lynch D., Furukawa Y., Griffin J., Piwnica-Worms H. et al. (1989) The product of the retinoblastoma susceptibility gene has properties of a cell cycle regulatory element. Cell 58: 1085-1095

30 Dulbecco R., Hartwell L. H. and Vogt M. (1965) Induction of cellular DNA synthesis by polyoma virus. Proc. Natl. Acad. Sci. USA 63: 403-410

31 Galanti N., Jonak G. J., Soprano K. J., Floros J., Kaczmarek L., Weissman S. et al. (1981) Characterization and biological activity of cloned simian virus 40 DNA fragments. J. Biol. Chem. 256: 6469-6474

32 Hatanaka M. and Dulbecco R. (1966) Induction of DNA synthesis by SV40. Proc. Natl. Acad. Sci. USA 56: 736-740

33 Henry P., Black P. H., Oxman M. N. and Weissman S. M. (1966) Stimulation of DNA synthesis in mouse cell line 3T3 by Simian virus 40. Proc. Natl. Acad. Sci. USA 56: $1170-1176$

34 Mueller C., Graessmann A. and Graessmann M. (1978) Mapping of early SV40-specific functions by microinjection of different early viral DNA fragments. Cell 15: $579-585$

35 Soprano K. J., Galanti N., Jonak G. J., McKercher S., Pipas J. M., Peden, K. W. et al. (1983) Mutational analysis of simian virus $40 \mathrm{~T}$ antigen: stimulation of cellular DNA synthesis and activation of rRNA genes by mutants with deletions in the T-antigen gene. Mol. Cell. Biol. 3: 214-219 
36 Tjian R., Fey G. and Graessmann A. (1978) Biological activity of purified simian virus $40 \mathrm{~T}$ antigen proteins. Proc. Natl. Acad. Sci. USA 75: $1279-1283$

37 Todaro G. J. and Green H. (1967) Simian virus 40 transformation and the period of cellular deoxyribonucleic acid synthesis. J. Virol. 1: 115-119

38 Ludlow J. W., DeCaprio J. A., Huang C. M., Lee W. H., Paucha E. and Livingston D. M. (1989) SV40 large T antigen binds preferentially to an underphosphorylated member of the retinoblastoma susceptibility gene product family. Cell 56: 57-65

39 Chen P. L., Scully P., Shew J. Y., Wang J. Y. and Lee W. H. (1989) Phosphorylation of the retinoblastoma gene product is modulated during the cell cycle and cellular differentiation. Cell 58: 1193-1198

40 Buchkovich K., Duffy L. A. and Harlow E. (1989) The retinoblastoma protein is phosphorylated during specific phases of the cell cycle. Cell 58: 1097-1105

41 Thomas N. S., Burke L. C., Bybee A. and Linch D. C. (1991) The phosphorylation state of the retinoblastoma $(\mathrm{RB})$ protein in G0/G1 is dependent on growth status. Oncogene 6: 317-322

42 Xu H. J., Hu S. X., Hashimoto T., Takahashi R. and Benedict W. F. (1989) The retinoblastoma susceptibility gene product: a characteristic pattern in normal cells and abnormal expression in malignant cells. Oncogene 4: 807-812

43 Mihara K., Cao X. R., Yen A., Chandler S., Driscoll B., Murphree A. L. et al. (1989) Cell cycle-dependent regulation of phosphorylation of the human retinoblastoma gene product. Science 246: $1300-1303$

44 Ludlow J. W., Shon J., Pipas J. M., Livingston D. M. and DeCaprio J. A. (1990) The retinoblastoma susceptibility gene product undergoes cell cycle-dependent dephosphorylation and binding to and release from SV40 large T. Cell 60: 387-396

45 Mittnacht S., Lees J. A., Desai D., Harlow E., Morgan D. O. and Weinberg R. A. (1994) Distinct sub-populations of the retinoblastoma protein show a distinct pattern of phosphorylation. EMBO J. 13: 118-127

46 Furukawa Y., DeCaprio J. A., Freedman A., Kanakura Y., Nakamura M., Ernst T. J. et al. (1990) Expression and state of phosphorylation of the retinoblastoma susceptibility gene product in cycling and noncycling human hematopoietic cells. Proc. Nat. Acad. Sci. 87: 2770-2774

47 Lees E. M. and Harlow E. (1995) Cancer and the cell cycle. In: Cell Cycle Control, pp. 228-263, Hutchison C. and Glover D. M. (eds), IRL Press, Oxford

48 Jensen D. E., Black A. R., Swick A. G. and Azizkhan J. C. (1997) Distinct roles for Sp1 and E2F sites in the growth/cell cycle regulation of the DHFR promoter. J. Cell. Biochem. 67: 24-31

49 Zwicker J. and Muller R. (1997) Cell-cycle regulation of gene expression by transcriptional repression. Trends Genet. 13: 3-6

50 Harbour J. W., Luo R. X., Dei Santi A., Postigo A. A. and Dean D. C. (1999) Cdk phosphorylation triggers sequential intramolecular interactions that progressively block $\mathrm{Rb}$ functions as cells move through G1. Cell 98: 859-869

51 Mittnacht S. (1998) Control of pRB phosphorylation. Curr. Opin. Geneti. Dev. 8: $21-27$

52 Taya Y., Yasuda H., Kamijo M., Nakaya K., Nakamura Y., Ohba Y. et al. (1989) In vitro phosphorylation of the tumor suppres- sor gene RB protein by mitosis-specific histone $\mathrm{H} 1$ kinase. Biochem. Biophys. Res. Commun. 164: 580-586

53 Connell-Crowley L., Harper J. W. and Goodrich D. W. (1997) Cyclin D1/Cdk4 regulates retinoblastoma protein-mediated cell cycle arrest by site-specific phosphorylation. Mol. Biol. Cell. 8: $287-301$

54 Zarkowska T. and Mittnacht S. (1997) Differential phosphorylation of the retinoblastoma protein by $\mathrm{G} 1 / \mathrm{S}$ cyclindependent kinases. J. Biol. Chem. 272: 12738-12746

55 Nelson D. A. and Ludlow J. W. (1997) Characterization of the mitotic phase $\mathrm{pRb}$-directed protein phosphatase activity. Oncogene 14: $2407-2415$

56 Nelson D. A., Krucher N. A. and Ludlow J. W. (1997) High molecular weight protein phosphatase type 1 dephosphorylates the retinoblastoma protein. J. Biol. Chem. 272: 4528-4535

57 Yen A. and Sturgill R. (1998) Hypophosphorylation of the RB protein in S and G2 as well as G1 during growth arrest. Exp. Cell Res. 241: 324-331

58 Cooper S., Yu C. and Shayman J. A. (1999) Phosphorylationdephosphorylation of retinoblastoma protein is not necessary for passage through the mammalian division cycle. IUBMB Life 1: 27-39

59 Alevizopoulos K., Vlach J., Hennecke S. and Amati B. (1997) Cyclin E and c-Myc promote cell proliferation in the presence of p16INK4a and of hypophosphorylated retinoblastoma family proteins. EMBO J. 16: 5322-5333

60 Lukas J., Herzinger T., Hansen K., Moroni M. C., Resnitzky D., Helin K. et al. (1997) Cyclin E-induced S phase without activation of the $\mathrm{pRb} / \mathrm{E} 2 \mathrm{~F}$ pathway. Genes Dev. 11: 14791492

61 Leone G., DeGregori J., Sears R., Jakoi L. and Nevins J. R. (1997) Myc and Ras collaborate in inducing accumulation of active cyclin E/Cdk2 and E2F. Nature 387: 422-426

62 Cooper S. (1991) Bacterial Growth and Division, Academic Press, San Diego

63 Cooper S. (1994) Analysis of the bacterial division cycle using membrane elution method. In: Methods in Molecular Genetics, pp. 234-257, Adolph K. (ed.), Academic Press, San Diego

64 Cooper S. (1987) On G0 and cell cycle controls. Bioessays 7: 220-223

65 Cooper S. (1998) On the proposal of a G0 phase and the restriction point. FASEB J. 12: 367-373

66 Cooper S. (1988) The continuum model and c-myc synthesis during the division cycle. J. Theor. Biol. 135: 393-400

67 Laiho M., DeCaprio J. A., Ludlow J. W., Livingston D. M. and Massague J. (1990) Growth inhibition by TGF-beta linked to suppression of retinoblastoma protein phosphorylation. Cell 62: $175-185$

68 Berndt N., Dohadwala M. and Liu C. W. (1997) Constitutively active protein phosphatase 1alpha causes Rb-dependent G1 arrest in human cancer cells. Curr. Biol. 7: 375-386

69 Cooper S. (1998) On the interpretation of the shortening of the G1-phase by overexpression of cyclins in mammalian cells. Exp. Cell Res. 238: $110-115$

70 Cooper S. (1979) A unifying model for the G1 period in prokaryotes and eukaryotes. Nature 280: $17-19$

71 Cooper S. (2000) The continuum model and G1-control of the mammalian division cycle. Prog. Cell Cycle Res. 4: 27-39 